\title{
Ploidy of Seeds from Odd-polyploid American Elm
}

\author{
Alan T. Whittemore and Zheng-Lian Xia \\ U.S. Department of Agriculture, Agricultural Research Service, U.S. National Arboretum, Wash- \\ ington, $D C$
}

AdDitional INDEX wORDs. flow cytometry, pentaploid, triploid, Ulmus americana

\begin{abstract}
Seeds from two odd-polyploid Ulmus americana L., both open-pollinated from surrounding tetraploid trees, were analyzed for nuclear genome size by using flow cytometry. Seeds from the triploid were predominantly aneuploid, with DNA content intermediate between triploid and tetraploid levels, but substantial numbers of tetraploid and pentaploid seeds were observed. No seeds of even ploidy were found in progeny of the pentaploid; seeds of the pentaploid were pentaploid, aneuploid with DNA content intermediate between tetraploid and pentaploid levels, or aneuploid with DNA content intermediate between pentaploid and hexaploid levels. Seeds from both trees often gave two peaks via flow cytometry, indicating the presence of two genetically distinct embryos in the same seed. The frequency of polyembryony in the sample is much higher than the frequency of seeds that yield multiple seedlings, suggesting that the formation of two genetically distinct embryos, followed by abortion of one embryo, is common in elms.
\end{abstract}

The american elm, Ulmus americana (Ulmaceae), is a tall, graceful tree that is native to the eastern United States and adjacent Canada (Bey, 1990). The species has frequently been planted as an ornamental and shade tree throughout temperate parts of the world, but use of the tree as an ornamental has been heavily limited by dutch elm disease, caused by two exotic wilt fungi, Ophiostoma ulmi (Buisman) C Nannf. and O. novo-ulmi Brasier (Brasier, 1991, 2001). Recent screening and breeding work has produced several cultivars that tolerate the disease (Townsend et al., 2005), and work is underway to breed this resistance into a wider variety of genetic backgrounds, with the aim of restoring american elm as an important and useful in both urban and forested landscapes (Pinchot et al., 2017).

Most elm species are diploid, with $2 n=28$ (Santamour and Ware, 1997). Polyploids are known in only one elm species, $U$. americana, with diploid and tetraploid populations known in the wild (Whittemore and Olsen, 2011; Whittemore and Xia, 2017) and two triploids known in cultivation (Santamour and Bentz, 1995; Sherald et al., 1994). Understanding the complex genetics of american elm is important if breeding and selection work is to be carried out efficiently.

The cultivated triploid NPS 3-487 (released commercially as U. americana 'Jefferson') was studied by Sherald et al. (1994), who found that $17 \%$ of the fruit on the triploid contained viable seed. This figure is low compared with tetraploid $U$. americana they studied, in which $89 \%$ of the fruit contained viable seed, but it is an unusually high figure for a sexually reproducing triploid. This tree is particularly interesting from a horticultural standpoint because it is known to show very high levels of tolerance to dutch elm disease (Townsend et al., 2005). In the course of surveying wild $U$. americana, a natural pentaploid

Received for publication 11 Sept. 2019. Accepted for publication 31 Jan. 2020. Published online 1 April 2020.

We thank Barry Stahl, Sue Bentz, Grace Kostel, Scott Aker, Kevin Tunison, and Christine Moore for their help in obtaining elm tissue for analysis; Richard Olsen for helpful discussions; and Robert Griesbach, Denny Townsend, and Scott Warnke for commenting on earlier versions of the manuscript.

A.T.W. is the corresponding author. E-mail: alan.whittemore@usda.gov.

This is an open access article distributed under the CC BY-NC-ND license (https://creativecommons.org/licenses/by-nc-nd/4.0/). was found in western Nebraska (discussed subsequently), and this also showed substantial seed set.

Spontaneous triploids and other odd polyploids are known in many groups of plants, but they are normally sexually sterile or nearly so (Grant, 1981). However, some triploids reproduce via apomixis (Whitton et al., 2008) or by unusual chromosomal systems that allow permanent propagation of odd ploidies (Grant, 1981). In cases where triploids set seed sexually, they can serve as a genetic bridge, allowing gene exchange between diploids and tetraploids, both in natural populations and in artificial plant breeding. Transfer of alleles between diploids and tetraploids has played an important evolutionary role in some taxa (Kim et al., 2008). The effectiveness of triploids as a bridge between diploids and tetraploids depends on the fertility of the triploid and the chromosomal complement of the backcrosses (Burton and Husband, 2000; Ramsey and Schemske, 1998). The meager literature on the chromosomal complements of backcrosses between triploids and plants with even ploidy numbers is reviewed by Ramsey and Schemske (1998). Although meiosis in triploids produces a preponderance of aneuploid pollen with $\approx 1.5$ sets of chromosomes, many triploids produce progeny that are euploid or close to euploid. The progeny of triploids fertilized with pollen from tetraploids were predominantly tetraploid [sometimes with one extra or one missing chromosome (i.e., $2 n=4 x \pm 1$ )] in the majority of cases, but this varied greatly among taxa, covering the whole range from $100 \%$ tetraploid (in Aquilegia chrysantha A. Gray $\times$ flabellata Siebold \& Zucc.) to $75 \%$ aneuploid (in Triticum durum Desf. $\times$ Aegilops longissima Schweinf. \& Muschl.) (Ramsey and Schemske, 1998).

The progeny of the triploid american elm NPS 3-487 that were described by Sherald et al. (1994) no longer exist, but the original parent tree is alive on the National Mall in Washington, DC, and still producing heavy crops of seed. To test whether these seeds are the result of sexual reproduction and to estimate the chromosomal complement of the seeds, nuclear DNA content was estimated by flow cytometry on a large sample of its seeds. Representative $U$. americana from surrounding plantings were also analyzed to estimate the ploidy level of the pollen available for fertilizing the triploid. A small sample of seeds was obtained from a wild pentaploid elm from 
Nebraska, and two tetraploid trees close to it were also analyzed.

\section{Materials and Methods}

Plant material. The american elm NPS 3-487 was first shown to be triploid by Sherald et al. (1994). It is part of a mass planting of american elm on the National Mall in Washington, $\mathrm{DC}$, and several hundred $U$. americana are growing within $1 \mathrm{~km}$ of the triploid, all of horticultural origin. A branch from NPS 3-487, laden with fruit almost ready to fall, was obtained from Barry Stahl (National Park Service) in Apr. 2011, and fruit were collected from this branch for analysis. Nuclear DNA content for the pistillate parent was previously obtained by analyzing foliage from cuttings of this tree (Whittemore and Olsen, 2011; Whittemore and Xia, 2017), and chromosome counts of $2 n=3 x=42$ were obtained by Sherald et al. (1994). The National Park Service, which maintains the National Mall, has germinated mass collections of seeds from elms in the vicinity. These progeny, which are representative of the genotypes growing in the vicinity of NPS 3-487, are growing in a National Park Service nursery on Daingerfield Island, VA. To estimate the ploidy of the pollen that NPS 3-487 was exposed to, leaf tissue was collected from 31 of these elms in June 2011, and flow cytometry was used to estimate their nuclear DNA content. Sampling surrounding trees from the National Mall was impractical because of the high canopy and restrictions on working in this site, which is heavily used by the public.

Meanwhile, small tissue samples were obtained from wild american elms to survey ploidy variation in the species (Whittemore and Olsen, 2011), and one wild elm from the Oglala National Grassland, Sioux County, NE, that had been collected in May 2010 (herbarium voucher Aker et al., NE-013, deposited in the herbarium of the U.S. National Arboretum), was determined to be pentaploid. This elm was part of a sparse native population forming a narrow riparian band along a tributary of Sand Creek (White River drainage). The appearance of the tree was in no way unusual, and no effort was initially made to collect a large sample. Flow cytometry was performed on six seeds from this wild elm. Foliage was obtained from the parent tree in Summer 2010 and analyzed by flow cytometry to determine the ploidy of the parent tree. Tissue was also obtained from two other $U$. americana in the same population (growing $\approx 300 \mathrm{~m}$ from the pentaploid) and analyzed by flow cytometry to determine the ploidy of likely pollen sources. Attempts to obtain more seeds from the pentaploid the following spring failed, as the tree had been killed in a fire.

FLOW CYTOMETRY. Seeds were dissected out of the fruit, care being taken to remove all fruit tissue from the seed. Fruit containing only undeveloped ovules were discarded. For leaf samples, $\approx 0.5 \mathrm{~cm}^{2}$ of fresh tissue from the leaf blade was used. Flow cytometry was performed following the protocol of Whittemore and Olsen (2011), except that it was not possible to run replicates of seed samples due to the small size of the seed, which was fully used for a single run.

Ploidy estimates. Previous work (Whittemore and Olsen, 2011; Whittemore and Xia, 2017) has established genome sizes for the different ploidy levels: $2 \mathrm{C}=3.1 \mathrm{pg}$ (diploid), $2 \mathrm{C}=4.7 \mathrm{pg}$ (triploid), and $2 \mathrm{C}=6.3 \mathrm{pg}$ (tetraploid). Previous work shows that genome size estimates of U. americana obtained using DAPI and PI are similar when Glycine $\max (\mathrm{L}$.) Merr.
'Williams 82 ' is used as the internal standard, so no correction needs to be applied when comparing PI and DAPI size estimates (A.T. Whittemore and Z.-L. Xia, unpublished data; Whittemore and Xia, 2017).

The endosperm in elms is crushed by the expanding embryo early in development. Seeds at or near maturity have no endosperm (Leliveld, 1935; López-Almansa et al., 2003, 2004; Zheng et al., 2017), and plants with even ploidy yield a single peak with flow cytometry (Whittemore and Olsen, 2011). Note, however, that Leliveld (1935) has described cases in Ulmus glabra Huds. in which the embryo aborts and endosperm tissue may persist in the aborted ovule. If this grew large enough to be mistaken for a seed, it would yield a single peak with high DNA content (discussed subsequently).

\section{Results}

Pollen SOURCE FOR THE TRIPLOID. The nuclear DNA content measured for the 31 trees representative of potential pollen parents in the vicinity of the triploid NPS 3-487 indicates that all are tetraploid mean 2C value for the 31 individuals is 6.35 $\mathrm{pg}$ and the coefficient of variation (CV) for estimates among the 31 individuals is $0.022 \mathrm{CV}$ for the three replicate runs performed for each individual averages 0.011 (mean of the 31 individual Cvs)] $\}$. Pollen from these trees is expected to be diploid. Surveys of seeds on wild tetraploid american elms from various parts of their range have revealed hexaploid seeds are produced at low frequency $[<1 \%$ of seeds (A.T. Whittemore and Z.-L. Xia, unpublished data)], suggesting that a small percentage of unreduced gametes, expected to be tetraploid, are produced. Ploidy variation in the pollen of the triploid has not been investigated. However, U. americana is self-incompatible (Johnson, 1946), and there are hundreds of other adult $U$. americana close to the triploid, so it is not likely that seeds are arising via self-pollination by the triploid tree.

Progeny of THe TRIPLOID. Whittemore and Olsen (2011) and Whittemore and Xia (2017) carried out flow cytometry on leaf tissue from the triploid NPS 3-487 and obtained an estimated nuclear DNA content of $2 \mathrm{C}=3 x=4.70 \mathrm{pg}$.

Nuclear DNA content was measured for 70 seeds of the triploid NPS 3-487. Nuclear DNA contents for all 70 seeds are shown in Fig. 1. Ten of the 70 seeds showed two clear peaks. In some, the two peaks were equal in size; in other cases, one or the other peak was larger (Fig. 2C and D). In many seeds that presented single peaks, the peaks were sharp and symmetrical (Fig. 2A). However, some showed peaks that are asymmetrical, with a shoulder on one side (Fig. 2B), suggesting that two populations of cells with different nuclear DNA content are present, but the difference is too small for full separation of the peaks. The 70 seeds can be placed in six categories for discussion, based on their nuclear DNA content (Table 1).

To obtain an estimate of seed set for this tree, 100 fruit were examined for seed development. Forty-eight of the 100 showed only unenlarged ovules, whereas the other 52 contained seeds. Appreciable variation was noted in seed size.

Pollen SOURCe fOR the PENTAPLOID. The nuclear DNA content measured from leaves of two trees growing in the vicinity of the Nebraska pentaploid, NE-013, indicates that both are tetraploid, with estimates of nuclear DNA content ranging from $2 \mathrm{C}=6.78$ to $6.90 \mathrm{pg}$ (mean $6.83 \mathrm{pg}, \mathrm{Cv} 0.011$ ).

Progeny of the Pentaploid. Nuclear DNA content for foliage from NE- 013 was estimated as $2 \mathrm{C}=7.835 \mathrm{pg}$ (mean of 


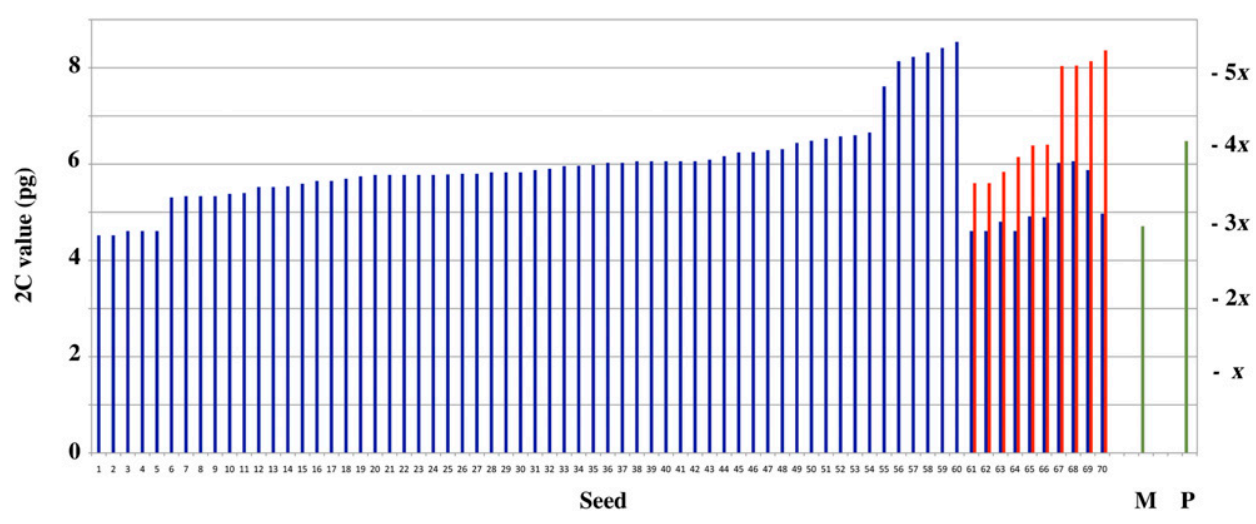

Fig. 1. Estimated nuclear DNA content (2C-value) for the cultivated triploid NPS 3-487 (Ulmus americana 'Jefferson') and nearby american elms. Samples are in the following order: Seeds, 70 seeds from the cultivated triploid [seeds yielding single peaks (blue bars), in ascending order of genome size, then, seeds yielding two peaks (paired blue and red bars), in ascending order of genome size of largest peak]; $\mathrm{M}=$ leaf tissue from the maternal parent (green bar), $\mathrm{P}=$ mean genome size for 31 nearby american elms, representing the potential pollen sources.

three runs, CV 0.028), indicating that it is pentaploid. Nuclear DNA content was estimated for six seeds from this parent (Fig. 3). Five of these had a single peak, with nuclear DNA content ranging from $2 \mathrm{C}=7.57$ to $8.70 \mathrm{pg}$, corresponding to aneuploids with of $\approx 5 x-3$ to $5 x+8$ sets of chromosomes. One of these appeared to be pentaploid, the others were aneuploid. The sixth seed had a pair of peaks at $2 \mathrm{C}=6.88$ and $7.60 \mathrm{pg}$, corresponding to $\approx 4 x+6$ and $4 x+11$ sets of chromosomes (Fig. 2E).

\section{Discussion}

Seed set in the triploid NPS 3-487 appeared to be higher than observed for the same tree by Sherald et al. (1994). The latter paper reported that 108 of 300 samaras $(37 \%)$ appeared to be full, whereas we observed that $52 \%$ of samaras in the $2011 \mathrm{crop}$ appeared to be full. However, Sherald et al. (1994) found that only 51 of these contained viable seed. The fact that Sherald et al. (1994) found that fewer than half of the samaras that appeared to be full contained viable seeds suggests that many of the 70 seeds analyzed in the current study also might not have been viable.

Embryos of $U$. americana comprise only enough tissue for a single flow cytometry run, so it was not possible to generate statistical measures of dispersion by using multiple runs from single seeds. However, other american elm samples were being studied at the same time that these seeds were being run, and for each of these other samples, three replicate preparations were independently chopped, stained, and run on the same machine using the same reagents and procedures. For 51 american elm samples, each run from three independent preparations at the same time as the seed samples or within 3 weeks of the seed samples, the average $\mathrm{CV}$ among independent preparations was 0.0225 , comparable to results obtained previously using the same machine and procedures (Whittemore and Olsen, 2011), so accuracy is expected to be good for this study. In addition, estimates of nuclear DNA content made by Whittemore and Olsen (2011) from samaras averaged $\approx 4 \%$ higher than estimates from leaf tissue, probably due to the presence of secondary compounds that affect DAPI staining (Whittemore and Olsen, 2011). Because the ploidy of the parent trees and potential pollen sources was estimated from leaf tissue, ploidy level of seeds may be slightly overestimated.
Most of the seeds produced by the triploid NPS 3-487 and the Nebraska pentaploid cannot be due to apomixis. Embryos produced apomictically are expected to have the same nuclear DNA content as the parent tree, which is $2 \mathrm{C}=4.70$ pg for NPS 3-487 and $2 \mathrm{C}=6.83 \mathrm{pg}$ for NE-013 (the Nebraska pentaploid). Only five of the 70 seeds from NPS 3-487 (7\%) and one of the six seeds from NE-013 (17\%) fell close to these values. The five triploid seeds from the triploid NPS 3487 were all small seeds that may not have been viable. The possibility that a few of these seeds may have been capable of producing apomictic progeny cannot be excluded from the current data, but apomixis has never been reported from Ulmus L., and there is no reason to postulate it here. Even if these seeds were viable, a percentage of seeds with near-parental chromosome counts is to be expected with normal fertilization and meiosis, given the ploidy level of the parents. The great majority of embryos [69 of $80(86 \%)$ ] had a nuclear DNA content over $5 \mathrm{pg}$, considerably higher than the mother, and must have resulted from the fertilization of egg cells by diploid pollen from neighboring tetraploid elms.

GENOME SIZE IN PROGENY FROM THE TRIPLOID. Aside from the five triploid seeds, which show no evidence of successful meiosis and fertilization, there are no seeds with nuclear DNA content below $2 \mathrm{C}=5.31 \mathrm{pg}$, corresponding to a ploidy level of $\approx 3.4$ (i.e., three complete sets of chromosomes and $\approx 6$ of 14 chromosomes from the fourth set). This suggests that either egg cells with chromosome numbers close to haploid or embryos with chromosome numbers close to triploid are being eliminated, a phenomenon known from many other triploid by tetraploid crosses (Ramsey and Schemske, 1998). However, the nuclear DNA content for the great majority of embryos was evenly distributed over a range from $2 \mathrm{C}=5.31$ to $6.65 \mathrm{pg}$. This suggests no tendency to favor tetraploid over aneuploid seed, as found in the progeny of triplod plants fertilized with pollen from tetraploids in many other genera (Ramsey and Schemske, 1998). The few pentaploid seeds most likely resulted from fertilization of unreduced egg cells by normal diploid pollen from the tetraploid parents, a phenomenon known from many triploid by tetraploid crosses. The presence of $<1 \%$ hexaploid seeds on wild tetraploid american elm (see above) confirms that elms normally produce unreduced gametes at low frequency, and production of unreduced gametes by an oddpolyploid hybrid elm has been described by Santamour (1971). The alternate possibility, that these pentaploids are produced by unreduced (tetraploid) pollen grains pollinating haploid egg cells on the triploid, seems unlikely. The bulk of seeds on the triploid, resulting from pollination by normal diploid pollen produced by the tetraploid pollen parents, appears as an array of seeds that varies evenly in DNA content over the range from triploid to tetraploid, suggesting that egg cells produced by the triploid parent vary evenly in DNA content over the range from haploid to diploid. Pollinations by unreduced (tetraploid) pollen would be expected to produce a similar 

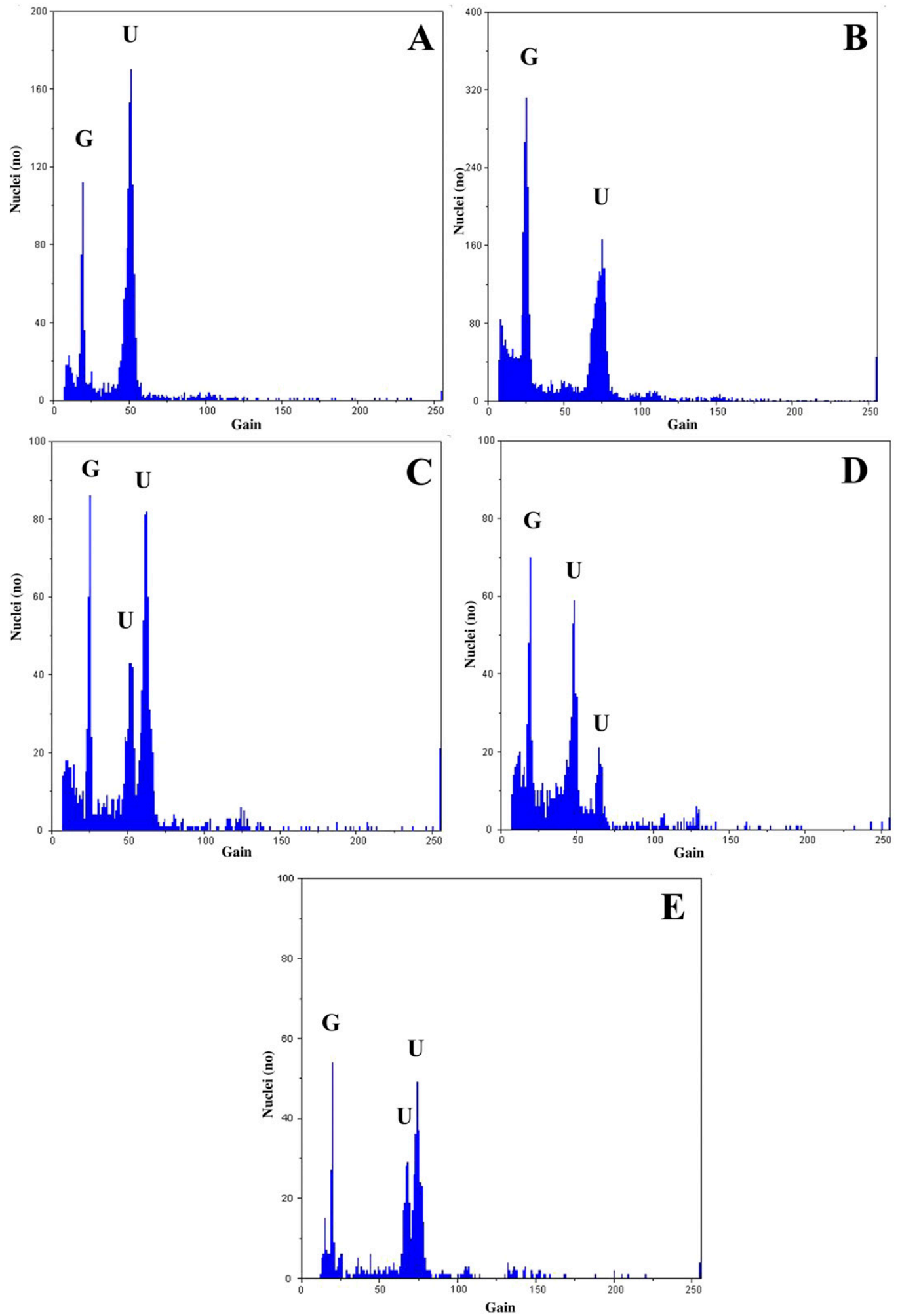

Fig. 2. Single flow cytometry runs for selected elm seeds. Labeling of peaks: $\mathrm{G}=$ Glycine max 'Williams 82 ' [internal size standard; $2 \mathrm{C} x=2.26 \mathrm{pg}(\mathrm{Chesnay}$ et al., 2007)]; U = Ulmus americana. (A-D) Seeds of the cultivated triploid NPS 3-487 (U. americana 'Jefferson'); (A) showing a sharp, symmetrical single peak; (B) showing a single asymmetrical peak with a shoulder on one side; (C) showing two peaks with the peak representing the higher $2 \mathrm{C}$ value larger; (D) showing two peaks with the peak representing the lower 2C value larger. (E) Seeds of NE-013 (the Nebraska pentaploid), showing two peaks.

array of seeds varying from pentaploid to hexaploid, rather than what is seen-several pentaploid seeds and no seeds with higher DNA content. The single seed with nuclear DNA content of $2 \mathrm{C}=7.65 \mathrm{pg}$, corresponding to an aneuploid number of $2 n=$
$4 x+\approx 10=\approx 66$, is harder to explain. Aneuploids close to pentaploid are not reported from other triploid by tetraploid crosses (Ramsey and Schemske, 1998). It has already been noted that Leliveld (1935) has described cases in U. glabra in 
Table 1. Nuclear DNA content of seeds from the triploid american elm, broken down into categories.

\begin{tabular}{|c|c|c|c|c|}
\hline Seeds (no.) & Peaks (no.) & 2C size range $(\mathrm{pg})$ & Inferred ploidy & Comments \\
\hline 5 & A single peak & $4.52-4.61$ & $3 x$ & All seeds are unusually small \\
\hline 49 & A single peak & $5.31-6.65$ & $3 x+5$ to $4 x$ & $\begin{array}{l}\text { Evenly distributed across this } \\
\text { size range }\end{array}$ \\
\hline 1 & A single peak & 7.39 & $4 x+10$ & \\
\hline 5 & A single peak & $8.14-8.54$ & $5 x$ & \\
\hline \multirow[t]{3}{*}{6} & Two peaks & & & \\
\hline & Peak 1 & $4.61-4.90$ & $3 x$ & \\
\hline & Peak 2 & $5.60-6.40$ & $3 x+8$ to $4 x$ & \\
\hline \multirow[t]{3}{*}{4} & Two peaks & & & \\
\hline & Peak 1 & $4.97-6.06$ & $3 x+3-13$ & \\
\hline & Peak 2 & $8.04-8.14$ & $5 x$ & \\
\hline
\end{tabular}

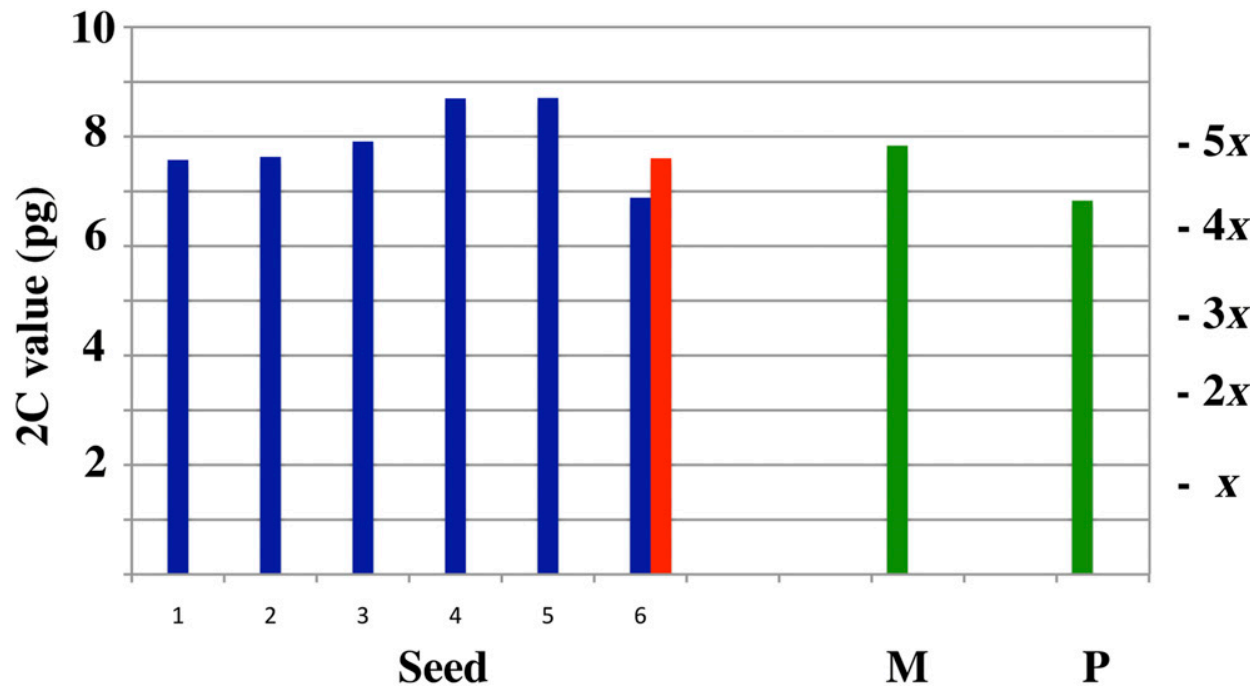

Fig. 3. Estimated nuclear DNA content (2C-value) for the wild tree NE-013 (the Nebraska pentaploid) and nearby american elms. Samples are in the following order: seeds, six seeds from NE-013 [seeds yielding single peaks (blue bars), in ascending order of genome size, then, the seeds yielding two peaks (paired blue and red bars)]; $\mathrm{M}=$ leaf tissue from the maternal parent (first green bar), $\mathrm{P}=$ mean genome size for two nearby american elms, representing the potential pollen sources (second green bar).

which the embryo aborts and endosperm tissue may persist in the aborted ovule. If this grew large enough to be mistaken for a seed, it would yield a single peak with high DNA content. Because endosperm in elms results from the union of one nucleus from the pollen grain and two from the embryo sac, endosperm from a triploid seed parent pollinated from a tetraploid elm could be anywhere from $4 x$ to $6 x$. Relatively few of the seeds had $2 \mathrm{C}$ values indicative of these ploidy levels, but it is not impossible that a small number of "seeds" actually represent ovules filled with endosperm. A satisfactory explanation will probably require study of more than a single seed.

These seeds are interpreted here as outcrosses with surrounding tetraploid elms because several studies have shown high levels of self-incompatibility in $U$. americana (Johnson, 1946; Townsend, 1975; Winieski, 1960). Some authors have found variable levels of self-incompatibility in american elm, and some clones may produce seeds via self-pollination (Ager and Guries, 1982; Lester, 1971), so it is possible that at least some of the seeds were set by self-pollination of the triploid NPS 3-487, although this seems unlikely given the heavy rain of $2 x$ pollen expected from the large number of mature american elms in the immediate vicinity of the triploid. Self-pollination of triploids in other groups of plants was reviewed by Ramsey and Schemske (1998) and is known to produce progeny high in tetraploids and aneuploids. However, pentaploids are seldom produced by triploid selfs, and aneuploid seeds from triploid selfs usually include at least some seeds with chromosome numbers that are diploid or intermediate between diploid and triploid, which was not observed here. However, the presence of seeds from self-pollination would not invalidate the main conclusions of this study.

Genome SIZE IN PROGENy FROM THE PENTAPLOID. The Nebraska pentaploid, NE-013, presented a series of aneuploid seeds with DNA content both lower and higher than the pentaploid parent. Seeds with a nuclear DNA content intermediate between tetraploid and pentaploid are expected when an egg resulting from meiosis in the pentaploid is pollinated by diploid pollen from one of the adjacent tetraploid trees. The two seeds with a nuclear DNA content clearly larger than pentaploid are more difficult to explain. They may represent pentaploid ovules pollinated by unreduced pollen grains from tetraploids, unless other pentaploids occur nearby or self-pollination is occurring in this sparse population. Satisfactory understanding of the genetics of pentaploid $U$. americana and its progeny will require study of a larger number of seeds and a more thorough sampling of potential pollen parents in the population, but it does serve to demonstrate that some of the processes observed in NPS 3-487 do occur in wild elms.

Seeds With MUltiple PeAKs. A number of seeds in both progenies (10 of 70 seeds in the triploid NPS 3-487, one of six in NE-013) showed two peaks, suggesting that two populations of cells with different nuclear DNA content are present. This phenomenon is not common in plants, but it reflects wellknown peculiarities of the structure and development of seeds in elms. Embryology and fertilization in $U$. americana were studied in detail by Shattuck (1905), with some additional study by Walker (1950). These studies found several unusual embryological features. In the embryo sac of $U$. americana, one of the antipodal cells often differentiates as a second egg, and single embryo sacs often contain two embryos, one chalazal and one antipodal. Because all four haploid nuclei produced by meiosis of the egg mother cell contribute to the embryo sac, the chalazal and antipodal eggs are derived from different meiotic products, and they will not be genetically identical; further, because a single ovule is often entered by more than one pollen tube, the two embryos will be sired by male gametes with different genotypes and may have different staminate parents. In addition, ovules of $U$. americana sometimes develop two embryo 
sacs. It therefore is normal for a single fruit of $U$. americana to produce two or three embryos that are genetically unlike. These processes are also seen in other species of Ulmus (D'Amato, 1940; Hjelmqvist and Grazi, 1965; Hofmeister, 1858; Nawaschin, 1898; Walker, 1938, 1950), suggesting that they are widespread in the genus.

Seeds of $U$. americana sometimes produce two or even three seedlings (Karnosky et al., 1979; Lester and Lee, 1974). The frequency with which seeds produce twins (two seedlings from one seed) or triplets (three seedlings from one seed) is low, although it varies among genotypes. Lester and Lee (1974) germinated $\approx 80,000$ seeds of tetraploid $U$. americana and reported that only 30 produced multiple seedlings ( 28 produced twins and two produced triplets), a frequency of only 0.0004 . Karnosky et al. (1979) germinated $\approx 250,000$ seeds of tetraploid $U$. americana from a seed source "shown to have a high multiple-seedling frequency," and reported obtained 1624 multiple seedlings (825 equal twins, 764 cryptic twins, and 35 triplets), a frequency of 0.0065 .

In contrast, the frequency of seeds that showed two peaks on flow cytometry was relatively high in both progenies: 14\% (10 of 70 seed) in the triploid NPS 3-487 and 17\% (one of six seed) in NE-013. The presence of seeds showing a single asymmetrical peak with a shoulder on one side (Fig. 2B), suggesting that there may be two peaks that are too close together to distinguish, suggests that the actual frequency with which two embryos are formed may be even higher. This strongly supports the conclusion of Shattuck (1905) and Walker (1950) that elms show a high frequency of simple polyembryony, in which multiple embryos in a seed result from different fertilization events involving different haploid nuclei. The difference between the high proportion of ungerminated seeds with multiple embryos observed in this study and those reported by Shattuck (1905) and Walker (1950), and the much lower proportion of seeds yielding multiple seedlings reported by Lester and Lee (1974) and Karnosky et al. (1979), suggests that formation of two genetically different embryos, followed by abortion of one embryo during seed development, must be common in the genus. Many plants produce more embryos than they are able to mature. This allows for competition between embryos and the survival of those that are most fit. Most cases that have been studied involve competition between developing fruit and seeds, rather than multiple embryos within one seed (Korbecka et al., 2002; Latta, 1995; Wiens, 1984), but the results of the competition should be similar in both cases. Competition between embryos in seeds showing simple polyembryony has been studied in some conifers, but these plants are selfcompatible and embryo competition mostly serves to eliminate embryos resulting from self-pollination (O'Connell and Ritland, 2005; Sorensen, 1982). Because U. americana is selfincompatible (Johnson, 1946), evolution of simple polyembryony cannot be driven by the consequences of self-pollination.

In the majority of seeds that produced two clearly separated peaks, one peak is triploid or pentaploid, suggesting that production of two peaks often involves proliferation of maternal tissue or the fertilization of unreduced gametes. The presence of asymmetrical peaks with a strong shoulder on one side, however, suggests that a substantial (but undetermined) number of seeds with a DNA content between triploid and tetraploid (the range characteristic of embryos resulting from the fusion of normal meiotic products) actually do have two embryos. Further research to clarify the situation would be useful because the production of multiple zygotes per seed, followed by selective elimination of less fit genotypes, would affect the frequency of genotypes in elm progeny, potentially altering the array of genotypes found in artificial crosses or in natural populations.

SigNifiCANCE OF THE RESUltS FOR ELM GenetiCs. Substantial numbers of tetraploid progeny were produced by the triploid, showing that triploids can function as a bridge allowing gene flow between diploid and tetraploid elms. However, the low percentage of tetraploid or near-tetraploid progeny will impede their function as a diploid-tetraploid bridge in natural populations despite the relatively high fertility of the triploids. In artificial breeding work, the use of flow cytometry to select tetraploid progeny at an early age may allow more efficient transfer of desired alleles from diploids and triploids into tetraploid breeding populations.

Further study of the role of polyembryony in Ulmus is desirable because the ability to form multiple embryos that are genetically unlike and the potential for selective abortion of some genotypes at the embryo level could influence both genetic processes in natural populations and the ability to obtain desirable character combinations in breeding programs. Multiple embryos with different origins are not normally seen with flow cytometry of seeds produced by true-breeding plants with even ploidy numbers because all embryos normally have the same nuclear DNA content. Flow cytometry of seeds produced by odd polyploids can reveal variation within seeds that is hidden in most cases, helping to clarify developmental processes.

The reproductive processes that produced the progeny of the Nebraska pentaploid are not clear from the available data. However, the data presented here confirm the occurrence of odd ploidies in wild populations of $U$. americana and also confirm that seeds with two peaks occur in native populations.

\section{Literature Cited}

Ager, A.A. and R.P. Guries. 1982. Barriers to interspecific hybridization in Ulmus americana. Euphytica 31:909-920.

Bey, C.F. 1990. Ulmus americana, p. 801-807. In: R.M. Burns and B.H. Honkala (eds.). Silvics of North America, vol. 2, hardwoods. U.S. Dept. Agr., For. Serv., Agr. Hdbk. 654.

Brasier, C.M. 1991. Ophiostoma novo-ulmi sp. nov., causative agent of current dutch elm disease pandemics. Mycopathologia 115:151-161.

Brasier, C.M. 2001. Rapid evolution of introduced plant pathogens via interspecific hybridization. Bioscience 51:123-133.

Burton, T.L. and B.C. Husband. 2000. Fitness differences among diploids, tetraploids, and their triploid progeny in Chamerion angustiflorum: Mechanisms of inviability and implications for polyploid evolution. Evolution 54:1182-1191.

Chesnay, C., A. Kumar, and S.R. Pearce. 2007. Genetic diversity of SIRE-1 retroelements in annual and perennial Glycine species revealed using SSAP. Cell. Mol. Biol. Lett. 12:103-110.

D’Amato, F. 1940. Embriologia di Ulmus campestris L. Nuovo Giornale Botanico Italiano 47:247-263.

Grant, V. 1981. Plant speciation. 2nd ed. Columbia Univ. Press, New York, NY.

Hjelmqvist, H. and F. Grazi. 1965. Studies on variation in embryo sac development. Second part. Bot. Not. 118:329-360.

Hofmeister, W. 1858. Neuere Beobachtungen über Embryobildung der Phanerogamen. Jahrbücher für wissenschaftliche Botanik 1:82-188.

Johnson, L.P.V. 1946. Fertilization in Ulmus with special reference to hybridization procedure. Can. J. Res. 24(1):1-3.

Karnosky, D.F., M.K. Redenbaugh, and R. Westfall. 1979. The use of anther culture and polyembryony in improving american elm, p. 9196. In: R.P. Guries (ed.). Proc. First North Central Tree Improvement 
Conf., Madison, WI. North Central Tree Improvement Assn., Madison, WI

Kim, M., M. Cui, P. Cubas, A. Gillies, K. Lee, M.A. Chapman, R.J. Abbott, and E. Coen. 2008. Regulatory genes control a key morphological and ecological trait transferred between species. Science 322:1116-1119.

Korbecka, G., P.G.L. Klinkhamer, and K. Vrieling. 2002. Selective embryo abortion hypothesis revisited - a molecular approach. P1. Biol. (Stuttgart) 4:298-310.

Latta, R.G. 1995. The effects of embryo competition with mixed mating on the genetic load in plants. Heredity 75:637-643.

Leliveld, J.A. 1935. Cytological studies in the genus Ulmus. II. The embryo sac and seed development in the common dutch elm. Recl. Trav. Bot. Neerl. 32:543-573.

Lester, D.T. 1971. Self-compatibility and inbreeding depression in american elm. Forest Sci. (Washington) 17:321-322.

Lester, D.T. and M.J.T. Lee. 1974. Twins and triplets of american elm. Forest Sci. (Washington) 20:142.

López-Almansa, J.C., J.R. Pannell, and L. Gil. 2003. Female sterility in Ulmus minor (Ulmaceae): A hypothesis invoking the cost of sex in a clonal plant. Amer. J. Bot. 90:603-609.

López-Almansa, J.C., E.C. Yeung, and L. Gil. 2004. Abortive seed development in Ulmus minor (Ulmaceae). Bot. J. Linn. Soc. 145:455-467.

Nawaschin, S. 1898. Uber das Verhalten des Pollenschlauches bei der Ulme. Bulletin de l'Académie Impériale des Sciences de Saint Pétersbourg Ser. 5 8:345-358.

O'Connell, L.M. and K. Ritland. 2005. Post-pollination mechanisms promoting outcrossing in a self-fertile conifer, Thuja plicata (Cupressaceae). Can. J. Bot. 83:335-342.

Pinchot, C.C., C.E. Flower, K.S. Knight, C. Marks, R. Minocha, D. Lesser, K. Woeste, P.G. Schaberg, B. Baldwin, D.M. Delatte, T.D. Fox, N. Hayes-Plazolles, B. Held, K. Lehtoma, S. Long, S. Mattix, A. Sipes, and J.M. Slavicek. 2017. Development of new dutch elm disease-tolerant selections for restoration of the american elm in urban and forested landscapes, p. 53-63. In: R.A. Sniezko, G. Man, V. Hipkins, K. Woeste, D. Gwaze, J.T. Kliejunas, and B.A. McTeague (technical coordinators). Gene conservation of tree species - Banking on the future. U.S. Dept. Agr., For. Serv., Pacific Northwest Res. Sta., Proc. Wkshp. Gen. Tech. Rep. PNW-GTR-963.
Ramsey, J. and D.W. Schemske. 1998. Pathways, mechanisms, and rates of polyploidy formation in flowering plants. Annu. Rev. Ecol. Syst. 29:467-501.

Santamour, F.S., Jr. and S.E. Bentz. 1995. Updated checklist of elm (Ulmus) cultivars for use in North America. J. Arboricult. 21:122-131.

Santamour, F.S., Jr. 1971. A triploid elm (Ulmus pumila x U. rubra) and its aneuploid progeny. Bull. Torrey Bot. Club 98:310-314.

Santamour, F.S., Jr. and G.H. Ware. 1997. Chromosome numbers of new Ulmus (elm) taxa introduced from China. Rhodora 99:148-151.

Shattuck, C.H. 1905. A morphological study of Ulmus americana. Bot. Gaz. 40:209-223.

Sherald, J.L., F.S. Santamour, Jr., R.K. Hajela, N. Hajela, and M.B. Sticklen. 1994. A dutch elm disease resistant triploid elm. Can. J. For. Res. 24:647-653.

Sorensen, F.C. 1982. The roles of polyembryony and embryo viability in the genetic system of conifers. Evolution (Lancaster) 36:725-773.

Townsend, A.M. 1975. Crossability patterns and morphological variation among elm species and hybrids. Silvae Genet. 24:18-23.

Townsend, A.M., S.E. Bentz, and L.W. Douglass. 2005. Evaluation of 19 american elm clones for tolerance to dutch elm disease. J. Environ. Hort. 23:21-24.

Walker, R.I. 1938. Macrosporogenesis and embryo development in Ulmus fulva. Bot. Gaz. 99:592-598.

Walker, R.I. 1950. Megasporogenesis and development of megagametophyte in Ulmus. Amer. J. Bot. 37:47-52.

Whittemore, A.T. and R. Olsen. 2011. Ulmus americana is a polyploid complex. Amer. J. Bot. 98:754-760.

Whittemore, A.T. and Z.-L. Xia. 2017. Genome size variation in elms (Ulmus sp.) and related genera. HortScience 52:547-553.

Whitton, J., C.J. Sears, E.J. Baack, and S.P. Otto. 2008. The dynamic nature of apomixis in the angiosperms. Int. J. Plant Sci. 169:169-182.

Wiens, D. 1984. Ovule survivorship, brood size, life history, breeding systems and reproductive success in plants. Oecologia 64:47-53.

Winieski, J.A. 1960. Artificial hybridization and grafting methods with Ulmus americana, p. 48-51. In: E.J. Schreiner (ed.). Proc. Seventh Northeastern Forest Tree Improvement Conf., Burlington, VT, 18-19 Aug. 1959.

Zheng, J.-Y., Y.-Z. Li, C.-C. Zhou, Y.-S. Lu, and X.-H. Wang. 2017. Study on embryology of Ulmus pumila L. Bull. Bot. Res. Guangxi 37:651-657. 